\title{
Quartz and Respirable Dust in the Dutch Construction Industry: A Baseline Exposure Assessment as Part of a Multidimensional Intervention Approach
}

\section{Erik van Deurssen ${ }^{1,2 *}$, Anjoeka Pronk ${ }^{2}$, Suzanne Spaan ${ }^{2}$, Henk Goede $^{2}$, Erik Tielemans ${ }^{2}$, Dick Heederik ${ }^{1}$ and Tim Meijster ${ }^{2}$}

\author{
1. Institute for Risk Assessment Sciences (IRAS), Utrecht University, PO Box 80178, 3508 TD Utrecht, The Netherlands
} 2. TNO, Utrechtseweg 48, PO Box 360, 3700 AJ Zeist, The Netherlands

*Author to whom correspondence should be addressed. Tel: +31-88-866-31-47; fax: +31-88-866-87-66; e-mail: erik.vandeurssen@tno.nl Submitted 3 December 2013; revised 28 February 2014; revised version accepted 4 March 2014.

\begin{abstract}
Quartz exposure can cause several respiratory health effects. Although quartz exposure has been described in several observational workplace studies, well-designed intervention studies that investigate the effect of control strategies are lacking. This article describes a baseline exposure study that is part of a multidimensional intervention program aiming to reduce quartz exposure among construction workers. In this study, personal respirable dust and quartz exposure was assessed among 116 construction workers (bricklayers, carpenters, concrete drillers, demolishers, and tuck pointers). Possible determinants of exposure, like job, tasks, and work practices, use of control measures, and organizational and psychosocial factors, were explored using exposure models for respirable dust and quartz separately. Stratified analyses by job title were performed to evaluate the effect of control measures on exposure and to explore the association between control measures and psychosocial factors. Overall, $62 \%$ of all measurements exceeded the Dutch occupational exposure limit for quartz and $11 \%$ for respirable dust. Concrete drillers and tuck pointers had the highest exposures for quartz and respirable dust 0.20 and $3.43 \mathrm{mg} \mathrm{m}^{-3}$, respectively). Significant predictors of elevated quartz exposure were abrasive tasks and type of material worked on. Surprisingly, in a univariate model, an increased knowledge level was associated with an increase in exposure. Although control measures were used infrequently, if used they resulted in approximately $40 \%$ reduction in quartz exposure among concrete drillers and tuck pointers. Only among concrete drillers, the use of control measures was associated with a higher score for social influence (factor 1.6); knowledge showed an inverse association with use of control measures for concrete drillers, demolishers, and tuck pointers. In conclusion, the detailed information on determinants of exposure, use of control measures, and constraints to use these control measures can be used for the determination and systematic prioritization of intervention measures used to design and implement our intervention strategy. This study underlines the need for multidisciplinary workplace exposure control strategies although larger study populations are necessary to determine a possible causal association between organizational and psychosocial factors and psychosocial factors and control measures.
\end{abstract}

(C) The Author 2014. Published by Oxford University Press on behalf of the British Occupational Hygiene Society. 
KEYWORD S : construction industry; control measures; exposure assessment; organizational factors; psychosocial factors; quartz; respirable dust

\section{INTRODUCTION}

Occupational exposure to quartz, used to mean respirable crystalline silica, results in a substantial disease burden in terms of excess occupational disease occurrence and excess mortality (Fedotov and Eijkermans, 2007; Brun et al., 2009). Diseases associated with quartz exposure are chronic respiratory diseases like chronic obstructive pulmonary disease (Rushton, 2007), silicosis including the progressive type (Tjoe Nij et al., 2003; Brown, 2009; Ehrlich et al., 2011), and lung cancer (Vida et al., 2010). In the Netherlands, approximately 300000 workers were employed in the construction industry in 2009, of whom almost $60 \%$ were potentially exposed to quartz (Lumens et al., 2009). In previous studies, several jobs and tasks within the Dutch construction industry showed exposure levels well above the Dutch occupational exposure limit (OEL) for quartz of $0.075 \mathrm{mg} \mathrm{m}^{-3}$ (Lumens and Spee, 2001; Tjoe Nij et al., 2003). Similar findings of excessive quartz exposure in the construction industry were reported in other countries in the European Union (Maciejewska, 2008) and in the USA (Yassin et al., 2005).

Information is available that describes the efficacy of control measures for (silica) dust under experimental conditions, either in a laboratory or under controlled conditions at the workplace (Fransman et al., 2008). However, under actual workplace conditions, organizational and psychosocial factors also contribute to the effectiveness of prevention and management of occupational exposures (Heederik and van Rooy, 2008). The importance of organizational engagement is generally acknowledged (LaMontagne et al., 2005), and a study focused on exposure determinants in a range of jobs suggested the importance of psychosocial factors on the exposure variability (Kromhout and Vermeulen, 2001). Occupational hygiene studies have paid much less attention to the role of these factors in controlling occupational exposures.

Hence, well-designed, multidimensional intervention studies should integrate technical (i.e. engineering), organizational, and psychosocial measures, in order to facilitate intervention strategies adopted in the workplace (Goldenhar et al., 2001; Lazovich et al., 2002; Kristensen, 2005; Seixas et al., 2011; Heederik et al., 2012).
The study described in this article forms the basis of a multidimensional intervention study aimed at reducing quartz exposure in the construction industry. The aim of this article is to provide baseline estimates of quartz exposure levels and obtain insight into the most important determinants associated with quartz exposure in the construction industry, including engineering and organizational and psychosocial aspects. This information will be used to develop and implement a multidimensional intervention program to reduce respirable dust and quartz exposure.

\section{METHODS}

\section{Study population}

The study population consisted of construction workers from eight construction companies, recruited via branch organizations. Companies were relatively specialized and had a limited number of job titles present. All companies and individual workers gave oral and written informed consent to participate. Relevant job categories were selected based on exposure levels identified in previous studies (Flanagan et al., 2003; Lumens et al., 2009), and in a pilot study, in which we visited a small selection of building sites and performed some exploratory measurements. Besides potential exposure levels, the size of the population was considered, resulting in the selection of the following jobs: bricklayers, carpenters, concrete drillers, demolishers, and tuck pointers. Although carpenters were expected to have lower quartz exposure, this category was included because it is assumed that they may be affected by bystander exposure. A more detailed task description per job category is provided in Table 1.

\section{Management questionnaire focused on organizational factors}

Employers were asked to fill in a questionnaire to get insight into the occupational safety and health policy of the company. This questionnaire was adapted from the Occupational Health and Safety Assessment Series (OHSAS) norm for health and safety management by selecting all questions focusing on hazardous 
Table 1. Description of included job categories in relation to main activities performed

\begin{tabular}{ll}
\hline Job category & Job description with most important tasks \\
\hline Bricklayer & $\begin{array}{l}\text { Mainly pointing mortar between bricks; several times per day, only for few } \\
\text { minutes, involved in preparing mortar }\end{array}$ \\
Carpenter & $\begin{array}{l}\text { Performs several tasks, predominantly framing and embedding concrete; handling } \\
\text { of (contaminated) materials }\end{array}$ \\
Concrete driller & $\begin{array}{l}\text { Mainly involved with drilling or sawing concrete or lime-sandstone (usually with } \\
\text { integrated water suppression serving as control measure); chopping out concrete }\end{array}$ \\
& $\begin{array}{l}\text { using jackhammer; recess milling of concrete or lime-sandstone; handling of } \\
\text { (contaminated) materials }\end{array}$ \\
Performs several tasks, including demolishing concrete objects/building (parts) \\
using jackhammer or demolishing crews; tidying the workplace by using bobcat/ \\
shovels; handling of (contaminated) materials \\
Mainly involved with chasing out of mortar between bricks with pneumatic \\
chipping hammers or hand-held grinders (usually without integrated ventilation \\
serving as control measure)
\end{tabular}

a Tasks with potential (high) exposure to respirable quartz dust.

substances (Anonymous, 2007). OHSAS is an audit evaluation system to assess whether organizations have a safety management system, documented and working in practice.

Among others, the questionnaire was focused on dust-reducing practices and included topics such as (i) presence and compliance of work procedures and workplace instructions; (ii) training of employees; (iii) management support of proactive health and safety culture (e.g. toolbox meetings on a fixed and regular schedule to stimulate discussion between employers and employees); and (iv) communication and feedback with equipment contractors to improve services.

\section{Personal exposure assessment and assessment of engineering factors}

Full-shift personal air samples (mean sampling time $7.3 \mathrm{~h}$ ) were taken from 116 construction workers between November 2011 and February 2012, of whom $22 \%$ were sampled repeatedly to enable the evaluation of the within worker variance. Respirable dust samples were collected using Dewell-Higgins cyclones mounted with a PVC filter (Millipore, pore size: $5.0 \mu \mathrm{m}$, diameter: $25 \mathrm{~mm}$ ), connected to a calibrated Gillian GilAir pump with an airflow of $21 \mathrm{~min}^{-1}$.
The amount of dust on filters was determined gravimetrically by pre- and post-weighing of filters on an analytical balance (Mettler) in a conditioned room. Filters were acclimatized at least $24 \mathrm{~h}$ prior to weighing (Health and Safety Executive (HSE), 2000). Quartz was determined by infrared spectroscopy and $\mathrm{X}$-ray diffraction (Health and Safety Executive (HSE), 2005). None of the samples collected had values below the limit of detection (LOD) for respirable dust of $0.15 \mathrm{mg}$, assessed as the average weight difference of the blank filters plus thrice the standard deviation. Seven samples (5\%) had values below the analytical LOD for quartz, which was $0.01 \mathrm{mg}$.

Throughout their shift, workers were observed using a structured walk-through survey to obtain detailed information on work activities (including task time), workspace, work practices, the type of tools used, type of material worked on, use of dustreducing techniques (i.e. control measures), and respiratory protective equipment (RPE).

\section{Worker questionnaire focused on psychosocial factors}

To explore the possible role of psychosocial factors, employees were asked to fill in a questionnaire on psychosocial factors potentially related to respirable dust 
and quartz exposure. Psychosocial factors covered topics like knowledge and beliefs regarding effectiveness of controls, risk perception, social influence, and motivation. A detailed description of these factors is given in Table 2. Knowledge of workers was assessed using a questionnaire with specific quartz dust-related questions. Adapted formats of existing standardized scales were applied to assess motivation, beliefs regarding effectiveness of controls, risk perception and social influence (Ajzen 1991; Geer et al., 2007), and risk propensity (Meertens and Lion, 2008). All psychosocial variables that were considered had a Cronbach value $\geq$ 0.7 , 'acceptable' based on the rules of thumb provided by George and Mallery (2010). Cronbach's alpha is a measure of internal consistency for different items that form a composite variable (Gliem and Gliem, 2003). A few psychosocial factors were included in the assessment (e.g. self-efficacy) but excluded in this analysis because of unreliable scales, i.e. low Cronbach value. All psychosocial variables were measured on a ratio scale with a range, as indicated in Table 2. Two separate questions addressed factors that may be (perceived as) a constraint or facilitator for a worker to perform dust-reducing work practices. In order to gain insight into the feasibility and reliability of the questionnaire, it was tested in a pilot study among 25 workers not involved in the next study phases.

\section{Statistical analyses}

All statistical analyses were performed using SAS v9.3 (SAS Institute Inc.). Samples below the analytical LOD of quartz were assigned a value of two thirds of the detection limit. All exposure data showed a skewed distribution, requiring the exposure data to be log transformed prior to statistical analysis. Descriptive statistics were calculated per job category. Spearman correlations between respirable dust and quartz concentrations were calculated. Determinants of exposure to respirable dust and quartz were explored using mixed effects models (PROC MIXED) in order to correct for possible correlation between repeated measurements (Rappaport et al., 1999). Worker was considered as random effect, whereas job category, task, work characteristics (e.g. worker-source orientation and worker-source distance), and organizational and psychosocial factors were introduced as fixed effects. Fixed effects were included as dichotomized variables, except psychosocial factors that were included as continuous variables. Variances were estimated as between-worker and within-worker variance components.

Model building comprised two steps. In the first step, univariate analyses were used to explore which determinants were associated with exposure to respirable dust and/or quartz. In the second step, determinants that were significantly associated with exposure were introduced stepwise into the model. For model building purposes, the level of significance for inclusion in the model was set at $P<0.10$.

Separate analyses were conducted to evaluate the effect of control measures, stratified by job category, because the use of specific control measures varied by job category. In addition, associations between psychosocial factors and the use of control measures were explored by job category using linear regression models (PROC REG).

\section{RESULTS}

\section{Population characteristics}

The study population consisted of male construction workers only (Table 3 ). Concrete drillers and tuck pointers were generally younger and had less work experience than workers in the other job categories. Carpenters had received vocational training most frequently, whereas concrete drillers were least often vocationally trained ( 86 versus $13 \%$, respectively).

\section{Organizational factors}

Participating companies in this study employed mainly permanent employees. Five out of eight companies stated that compliance with work procedures and workplace instructions regarding dust-reducing practices was supervised by their management. Two companies actively provided training regarding dustreducing work practices to their personnel. Within three companies, management-supported proactive health and safety culture focused on dust-reducing practices. Five companies consulted with their equipment contractors on improving their services regarding dust-reducing practices.

\section{Personal exposure levels}

In total, 149 full-shift personal samples were collected from 116 workers. Table 3 shows the average exposure levels for each job category. Exposure to respirable 
Table 2. Description of psychosocial factors

\begin{tabular}{|c|c|c|c|c|c|c|c|}
\hline Scale & $N^{a}$ & $\begin{array}{l}\text { Based on } \\
\text { (references) }\end{array}$ & Type & $\begin{array}{l}\text { Cronbach } \\
\text { value }\end{array}$ & Scale & Description & $\begin{array}{l}\text { Examples of } \\
\text { questions }\end{array}$ \\
\hline Beliefs & 10 & $\begin{array}{l}\text { Adapted existing } \\
\text { questionnaire } \\
\text { (Ajzen, 1991) }\end{array}$ & Likert $5^{\mathrm{b}}$ & 0.75 & $1-5$ & $\begin{array}{l}\text { Indication of an } \\
\text { individual's beliefs } \\
\text { in the effectiveness } \\
\text { of various exposure } \\
\text { controls and } \\
\text { dust-reducing } \\
\text { work practices }\end{array}$ & $\begin{array}{l}\text { - Ventilation } \\
\text { systems or wetting } \\
\text { techniques are } \\
\text { effective in reducing } \\
\text { quartz dust } \\
\text { - Dust-reducing } \\
\text { work practices are } \\
\text { effective in reducing } \\
\text { quartz dust }\end{array}$ \\
\hline Knowledge & 8 & Self-developed & c & n.a. ${ }^{d}$ & $0-1$ & $\begin{array}{l}\text { Estimation of } \\
\text { an individual's } \\
\text { knowledge regarding } \\
\text { exposure sources, } \\
\text { controls, substances, } \\
\text { routes of exposure, } \\
\text { and short- and } \\
\text { long-term effects } \\
\text { of quartz dust }\end{array}$ & $\begin{array}{l}\text { - Which task causes } \\
\text { excessive quartz } \\
\text { dust emission? } \\
\text { - Which products } \\
\text { contain the highest } \\
\text { percentage of } \\
\text { quartz? } \\
\text { - Which long-term } \\
\text { health effects may } \\
\text { occur when you are } \\
\text { exposed to quartz } \\
\text { dust (for prolonged } \\
\text { periods)? }\end{array}$ \\
\hline Motivation & 11 & $\begin{array}{l}\text { Adapted existing } \\
\text { questionnaire } \\
\text { (Ajzen, 1991) }\end{array}$ & Likert $5^{\mathrm{b}}$ & 0.92 & $1-5$ & $\begin{array}{l}\text { Indication of an } \\
\text { individual's intention } \\
\text { (or motivation) } \\
\text { to use exposure } \\
\text { controls and dust- } \\
\text { reducing work } \\
\text { practices }\end{array}$ & $\begin{array}{l}\text { To what extent are } \\
\text { you planning to use } \\
\text { dust-reducing work } \\
\text { practices during } \\
\text { cleaning of your } \\
\text { workplace? } \\
\text { - To what extent are } \\
\text { you planning to } \\
\text { use dust-reducing } \\
\text { practices during } \\
\text { your work? }\end{array}$ \\
\hline $\begin{array}{l}\text { Risk } \\
\text { perception }\end{array}$ & 6 & $\begin{array}{l}\text { Adapted existing } \\
\text { questionnaire } \\
\text { (Ajzen, 1991; } \\
\text { Geer et al., 2007) }\end{array}$ & Likert $5^{\mathrm{b}}$ & 0.70 & $1-5$ & $\begin{array}{l}\text { Indication of an } \\
\text { individual's } \\
\text { perception of risk } \\
\text { of quartz dust and } \\
\text { susceptibility to } \\
\text { short- or long-term } \\
\text { health effects }\end{array}$ & $\begin{array}{l}\text { - How risky is quartz? } \\
\text { In your opinion, } \\
\text { what are the } \\
\text { chances that you } \\
\text { will develop health } \\
\text { complaints in the } \\
\text { short term when } \\
\text { working with } \\
\text { quartz? }\end{array}$ \\
\hline
\end{tabular}


Table 2. continued

\begin{tabular}{|c|c|c|c|c|c|c|c|}
\hline Scale & $N^{\mathrm{a}}$ & $\begin{array}{l}\text { Based on } \\
\text { (references) }\end{array}$ & Type & $\begin{array}{l}\text { Cronbach } \\
\text { value }\end{array}$ & Scale & Description & $\begin{array}{l}\text { Examples of } \\
\text { questions }\end{array}$ \\
\hline $\begin{array}{l}\text { Risk } \\
\text { propensity }\end{array}$ & 6 & $\begin{array}{l}\text { Adapted existing } \\
\text { questionnaire } \\
\text { (Meertens and } \\
\text { Lion, 2008) }\end{array}$ & Likert $5^{\mathrm{b}}$ & 0.68 & $1-5$ & $\begin{array}{l}\text { Estimate of an } \\
\text { individual's } \\
\text { inclination to seek } \\
\text { or avoid general } \\
\text { (health) risks }\end{array}$ & $\begin{array}{l}\text { - Health is everything } \\
\text { for me } \\
\text { - I preferably avoid } \\
\text { risks } \\
\text { - I take risks regularly }\end{array}$ \\
\hline $\begin{array}{l}\text { Social } \\
\text { influence }\end{array}$ & 3 & $\begin{array}{l}\text { Adapted existing } \\
\text { questionnaire } \\
\text { (Ajzen, 1991) }\end{array}$ & Likert $5^{\mathrm{b}}$ & 0.67 & $1-5$ & $\begin{array}{l}\text { Indication whether } \\
\text { an individual is } \\
\text { influenced by } \\
\text { co-workers or } \\
\text { supervising } \\
\text { personnel to use } \\
\text { exposure controls } \\
\text { and dust-reducing } \\
\text { work practices }\end{array}$ & $\begin{array}{l}\text { - My colleagues } \\
\text { regularly remind } \\
\text { each other of } \\
\text { dust-reducing work } \\
\text { practices } \\
\text { - I only use } \\
\text { dust-reducing work } \\
\text { practices when my } \\
\text { supervisor is in the } \\
\text { neighbourhood }\end{array}$ \\
\hline
\end{tabular}

${ }^{\mathrm{a}} \mathrm{N}=$ number of questions per scale.

${ }^{b}$ Questions using Likert-type scales comprised statements concerning the psychosocial factor of interest using five response possibilities, e.g. ranging between agree and disagree, likely and unlikely. All question outcomes were scaled in the same direction, depending on the type of question. Response categories were adjusted if statement was asked inversely.

'Knowledge scale consisted of dichotomous questions (true/false) and multiple choice, which were transformed into a ratio scale.

${ }^{\mathrm{d} A}$ Cronbach value is not useful for the knowledge scale where diverse topics are evaluated.

dust was highest among tuck pointers, whereas concrete drillers were exposed to the highest quartz levels. The overall geometric mean (GM) was $0.88 \mathrm{mg}$ $\mathrm{m}^{-3}$ for respirable dust [geometric standard deviation (GSD) 4.23 ] and $0.10 \mathrm{mg} \mathrm{m}^{-3}$ for quartz (GSD 3.84). The overall correlation coefficient $(r)$ between respirable dust and quartz was 0.76 (range 0.24-0.84 for different job categories), with the largest association for concrete drillers. The full-shift exposure measurements showed quartz concentrations exceeding the Dutch OEL for quartz $\left(0.075 \mathrm{mg} \mathrm{m}^{-3}\right)$ in $62 \%$ of the measurements, whereas the Dutch OEL for respirable dust $\left(5.00 \mathrm{mg} \mathrm{m}^{-3}\right)$ was exceeded in $11 \%$ of the measurements.

\section{Psychosocial factors}

The questionnaire regarding psychosocial factors was administered to all 116 workers. However, eighteen workers did not fill in the questionnaire because of language barriers $(n=2)$ or lack of interest. Among all workers who completed the questionnaire, two main reasons were mentioned to use control measures and/ or to perform dust-reducing work practices if possible: 'It is better for my own health' (89\%) and 'It is less inconvenient for my eyes or my airways' (67\%). Ergonomically poorly designed tools that adversely affected their productivity were mentioned as the most important constraint to apply dust-reducing work practices.

Overall, carpenters had the highest score for knowledge regarding dust exposure and its possible health effects ( 0.8 on a scale of 0 to 1$)$. Tuck pointers had the lowest scores for risk perception, beliefs regarding effectiveness of controls, social influence, and motivation compared with other job categories, whereas concrete drillers and demolishers had the highest scores. Psychosocial factor scores are presented in Table 3. Because we hypothesized that the way a company deals with their occupational safety and health policy may affect psychosocial aspects of the workers, we investigated the association between organizational and psychosocial factors. Concrete drillers were present in three companies. All of these three companies offered training on dust reduction practices to their employees, 
Table 3. Population characteristics, mean exposure to respirable dust, and quartz and psychosocial factors by job category

Job category

Bricklayer Carpenter

\section{Concrete} driller

Overall

Population characteristics

$\begin{array}{lllllll}\text { Age }(\text { years })^{\mathrm{a}} & 46(24-58) & 37(19-58) & 37(20-48) & 41(20-56) & 39(16-54) & 39 \\ \text { Work experience } & 27(7-42) & 18(3-44) & 15(3-28) & 19(3-39) & 17(1-36) & 18\end{array}$
(years) $^{\mathrm{a}}$

Received vocational 78

86

13

67

50

55

training (\%)

Exposure measurements

$k$
$n$
$N$

2

1

921

3

21

12

21

3

38

7

46

0.22 (2.97)

$0.86(3.05)$

1.17 (3.80)

3.43 (3.02)

0.88 (4.23)

Range

0.04-0.59

0.03-4.67

0.02-10.86

0.09-33.76

0.36-17.04

$0.02-33.76$

Quartz $\left(\mathrm{mg} \mathrm{m}^{-3}\right)$

GM (GSD)
Range

$0.02(1.73)$

$0.02(2.30)$

$0.20(2.75)$

$0.12(2.86)$

0.18 (2.18)

$0.10(3.84)$

Range

0.01-0.04

0.01-0.09

$0.01-1.36$

$0.01-0.91$

$0.02-0.80$

$0.01-1.36$

Exceedance OEL

$$
0
$$

0

4

11

40

11

respirable dust (\%)

Exceedance

0

5

97

71

92

62

Psychosocial factors

Beliefs

Knowledge

Motivation

Risk perception

Risk propensity

Social influence

$$
\begin{array}{llllll}
3.6(2.7-4.8) & 3.8(3.1-4.8) & 3.9(2.6-4.9) & 4.1(2.5-5.0) & 3.3(1.8-4.3) & 3.8 \\
0.6(0.3-0.9) & 0.8(0.5-1.0) & 0.7(0.4-0.9) & 0.7(0.3-0.9) & 0.7(0.4-0.9) & 0.7 \\
3.9(2.3-5.0) & 3.8(2.6-4.9) & 3.9(2.9-5.0) & 4.2(3.0-5.0) & 3.2(1.9-4.1) & 3.9 \\
3.6(2.2-4.7) & 3.6(2.5-4.5) & 3.7(2.7-4.7) & 3.6(2.5-5.0) & 3.5(2.5-4.7) & 3.6 \\
3.6(2.7-4.3) & 3.6(2.7-4.3) & 3.6(2.7-4.3) & 3.6(2.7-4.3) & 3.4(2.7-4.2) & 3.5 \\
2.9(2.2-3.7) & 3.0(1.4-4.2) & 3.5(2.2-4.6) & 3.6(2.2-5.0) & 3.1(2.0-5.0) & 3.3
\end{array}
$$

$k=$ number of companies per job category; $n=$ number of subjects per job category; $r=$ number of subjects with repeated measurements per job category; $N=$ total number of personal air samples per job category.

${ }^{a}$ Average (min-max).

${ }^{\mathrm{b}}$ Geometric mean (geometric standard deviation). 
Table 4. Estimates of model variables in final mixed effects models of the log-transformed exposure to respirable dust and quartz

\begin{tabular}{|c|c|c|c|c|c|}
\hline \multirow[t]{2}{*}{ Model variables (fixed effects) } & \multirow[t]{2}{*}{$n^{\mathrm{a}}$} & \multicolumn{2}{|c|}{ Respirable dust } & \multicolumn{2}{|c|}{ Quartz } \\
\hline & & $\beta$ & $P$ value & $\beta$ & $P$ value \\
\hline Intercept $\mathrm{t}^{\mathrm{b}}$ & & -4.18 & $* * *$ & -5.98 & $* * *$ \\
\hline \multicolumn{6}{|l|}{ Job category } \\
\hline Carpenter & 21 & 1.42 & $0.12^{* * * *}$ & 1.27 & $0.14^{* * * *}$ \\
\hline Concrete driller & 46 & 2.39 & $0.01^{*}$ & 3.54 & ** \\
\hline Demolisher & 45 & 1.82 & $0.05^{*}$ & 2.81 & ** \\
\hline Tuck pointer & 25 & 3.02 & *** & 2.63 & $* * *$ \\
\hline Bricklayer & 12 & Ref. & & & \\
\hline \multicolumn{6}{|l|}{ Tasks } \\
\hline Demolishing & 24 & 1.05 & $0.01^{*}$ & & \\
\hline Drilling & 38 & & & 0.29 & $0.15^{* * * *}$ \\
\hline Handling & 89 & -0.32 & $0.02^{*}$ & -0.39 & $0.01^{*}$ \\
\hline Milling & 4 & 1.24 & ** & & \\
\hline Sanding & 4 & 1.52 & ** & 1.06 & $0.01^{*}$ \\
\hline \multicolumn{6}{|l|}{ Location } \\
\hline Indoors & 93 & 1.57 & *** & 1.54 & $* * *$ \\
\hline Outdoors & 56 & Ref. & & & \\
\hline \multicolumn{6}{|l|}{ Distance to source } \\
\hline Near field & 60 & 0.54 & ** & & \\
\hline Far field & 87 & Ref. & & & \\
\hline \multicolumn{6}{|l|}{ Work orientation } \\
\hline Shoulder level & 100 & 0.46 & ** & & \\
\hline \multicolumn{6}{|l|}{ Product } \\
\hline Cement & 36 & 2.08 & $0.02^{*}$ & 2.08 & $0.01^{*}$ \\
\hline Ceramics & 11 & 0.99 & ** & & \\
\hline \multicolumn{6}{|l|}{ Control measure } \\
\hline Integrated LEV & 15 & -0.62 & $0.02^{*}$ & -0.53 & $0.03^{*}$ \\
\hline Stationary extraction unit & 8 & 0.55 & $0.12^{* * * *}$ & & \\
\hline Integrated water suppression & 34 & & & -0.36 & $0.10^{* * * *}$ \\
\hline Spraying water & 9 & & & -0.46 & $0.09^{*}$ \\
\hline Var_b ${ }_{w}(C I)^{c}$ & & \multicolumn{2}{|c|}{$0.38(0.24-0.69)$} & \multicolumn{2}{|c|}{$0.27(0.14-0.66)$} \\
\hline
\end{tabular}


Table 4. continued

\begin{tabular}{|c|c|c|c|}
\hline \multirow[t]{2}{*}{ Model variables (fixed effects) } & \multirow[t]{2}{*}{$n^{\mathrm{a}}$} & Respirable dust & Quartz \\
\hline & & $P$ value & $P$ value \\
\left.\hline${\operatorname{Var} \_w_{w}}_{(C I}\right)^{d}$ & & $0.23(0.14-0.43)$ & $0.31(0.20-0.55)$ \\
\hline Total explained variability & & $71 \%$ & $71 \%$ \\
\hline
\end{tabular}

${ }^{\mathrm{a}}$ Number of observations with factor present.

'The intercept gives the exposure level working as a bricklayer, working outside, far field, not working on shoulder level, not performing any of the tasks, not working with the mentioned products, and not using any of the control measures included in the multivariate model.

'Variance component between workers (confidence interval).

${ }^{\mathrm{d}}$ Variance component within workers (confidence interval).

Significant at ${ }^{*} P<0.10 ;{ }^{* *} P \leq 0.005 ;{ }^{* * *} P \leq 0.0001$; ${ }^{* * *}$ borderline significant $0.10 \leq P \leq 0.20$.

probably resulting in a similar score ( 0.7 on a scale of 0 to 1 ) for knowledge of their employees. One company employing concrete drillers did not supervise on compliance of work procedures and workplace instructions, which may be indicative for the lower score on social influence ( 3.5 on a scale of $1-5$ ) compared with concrete drillers with supervision in two other companies ( 4.2 and 4.3 on a scale of $1-5$ ). A similar indicative, but weak association was found when comparing tuck pointers among three companies with regard to social influence. None of these associations were statistically significant (data not shown).

\section{Determinants of exposure}

Table 4 shows the final mixed effects models for respirable dust and quartz exposure. Concrete drillers had on average a 40 times higher exposure to quartz than the reference group, 'bricklayers'. Working indoors resulted in approximately 4.5 times higher exposure to respirable dust and quartz. The activities sanding and drilling were significantly associated with elevated respirable dust and quartz exposure (factors ranging from 1.5 to 4.5 ). Exposure to respirable dust increased when working at shoulder level or near-field workersource distance. Integrated water suppression and the spraying of water resulted in almost 1.5 times lower exposure to quartz, whereas integrated local exhaust ventilation (LEV) reduced exposure to respirable dust and quartz by a factor 2 . Use of a stationary extraction unit was not significantly associated with exposure. All determinants [e.g. task, product, work practices (i.e. worker-source orientation and worker-source distance), and control measure] by job category as well as their association with exposure in the univariate models are presented in the Supplementary data, available at Annals of Occupational Hygiene online.

Organizational factors did not show any relation with exposure, in both the univariate and multivariate models. The psychosocial factors also were not associated with exposure in the multivariate models. However, the univariate models did show some significant associations. Because we were explicitly interested in psychosocial factors, the results for the univariate associations are shown in Table 5. Only for one of the psychosocial factors, i.e. knowledge, there were indications for an association with respirable dust $(P=0.03)$ and quartz $(P=0.07)$ exposure in a univariate model, with increasing exposure levels when the knowledge level increased. Larger social influence seemed associated with increased quartz exposure levels only $(P<0.01)$. The final models explained 72 and $83 \%$ of the between-worker variance, and 69 and $22 \%$ of the day-to-day variability for respirable dust and quartz, respectively.

\section{Control measures}

Because the use of control measures was correlated with job category, we separately analysed the effect of control measure on exposure by job category. Control measures were particularly used during abrasive tasks among certain job categories, i.e. concrete driller, demolisher, and tuck pointer. The effect of control measures by job category is shown in Table 6 . Examples of the control measures that were available during the field study are shown in Fig. 1. Concrete drillers used control measures more frequently (83\%) than demolishers (38\%) and tuck pointers (28\%). Tool-integrated water suppression, used by concrete drillers during drilling and sawing and characterized 
Table 5. Psychosocial factors and associations with respirable dust and quartz exposure as estimated in a mixed model

\begin{tabular}{|c|c|c|c|c|}
\hline \multirow[t]{2}{*}{ Scale } & \multicolumn{2}{|c|}{ Respirable dust } & \multicolumn{2}{|c|}{ Quartz } \\
\hline & $\beta$ & $P$ value & $\beta$ & $P$ value \\
\hline Beliefs & -0.30 & 0.19 & -0.06 & 0.80 \\
\hline Knowledge & -2.22 & $0.03^{*}$ & -1.69 & $0.07^{*}$ \\
\hline Motivation & -0.18 & 0.37 & 0.03 & 0.88 \\
\hline Risk perception & -0.09 & 0.73 & -0.05 & 0.84 \\
\hline Risk propensity & -0.49 & $0.13^{* * *}$ & -0.30 & 0.32 \\
\hline Social influence & 0.15 & 0.39 & 0.51 & ** \\
\hline
\end{tabular}

Significant at ${ }^{*} P<0.10 ;{ }^{* *} P \leq 0.005 ;{ }^{* * *}$ borderline significant $0.10 \leq P \leq 0.20$.

Table 6. Effect of identified control measures on exposure to respirable dust and quartz by job category

\begin{tabular}{lllll}
\hline Job category & $N$ & Control measure of interest $(n)$ & \multicolumn{2}{l}{ Effect on exposure $(P$ value $)$} \\
\hline Concrete driller & 46 & Integrated LEV (7) & Respirable dust & Quartz \\
\hline \multirow{2}{*}{ Demolisher } & 46 & Integrated water suppression (31) & $1.0(0.96)$ & $0.9(0.86)$ \\
& 45 & Stationary extraction unit (8) & $9.5(0.00)^{*}$ & $0.6(0.17)^{* *}$ \\
Tuck pointer & 45 & Spraying water (9) & $0.5(0.10)^{* *}$ & $0.9(0.70)$ \\
& 25 & Integrated LEV (7) & $0.18)^{* *}$ \\
\end{tabular}

$N=$ total number of measurements per job category; $n=$ number of measurements where this control is used for the given job category.

Significant at ${ }^{*} P<0.10 ;{ }^{* *}$ borderline significant $0.10 \leq P \leq 0.20$.

by a hose connection on the tool, resulted in a nonsignificant $40 \%$ reduction in quartz exposure $(P>0.10)$. For tuck pointers, the use of industrial vacuum cleaners fitted to a centralized extraction ventilation system showed a borderline significant exposure reduction of $60 \%$ for respirable dust and $45 \%$ for quartz $(P=0.11)$. Demolishers using a stationary extraction unit had a 9-fold higher exposure to respirable dust compared with demolishers not using this type of control measure. Spraying water as control measure demonstrated a borderline significant reduction in exposure to respirable dust $(P=0.10)$ among demolishers.

\section{Psychosocial aspects and use of control measures} We explored whether the use of control measures was associated with psychosocial factors by job category because this association might explain why psychosocial factors were not significantly associated with exposure in the final multivariate model. Surprisingly, concrete drillers, demolishers, and tuck pointers with a higher knowledge level less often used control measures (factor $0.3-0.8 ; P>0.10)$. Only among concrete drillers, a higher score for social influence from colleagues or supervisors seemed to result in a significant 1.6 increase $(P<0.001)$ in the use of control measures (data not shown).

\section{DISCUSSION}

This is the first study documenting the potential role of organizational and psychosocial determinants in relation to underlying exposure to respirable dust and quartz. Together with the baseline exposure assessment, this information will be integrated into an 

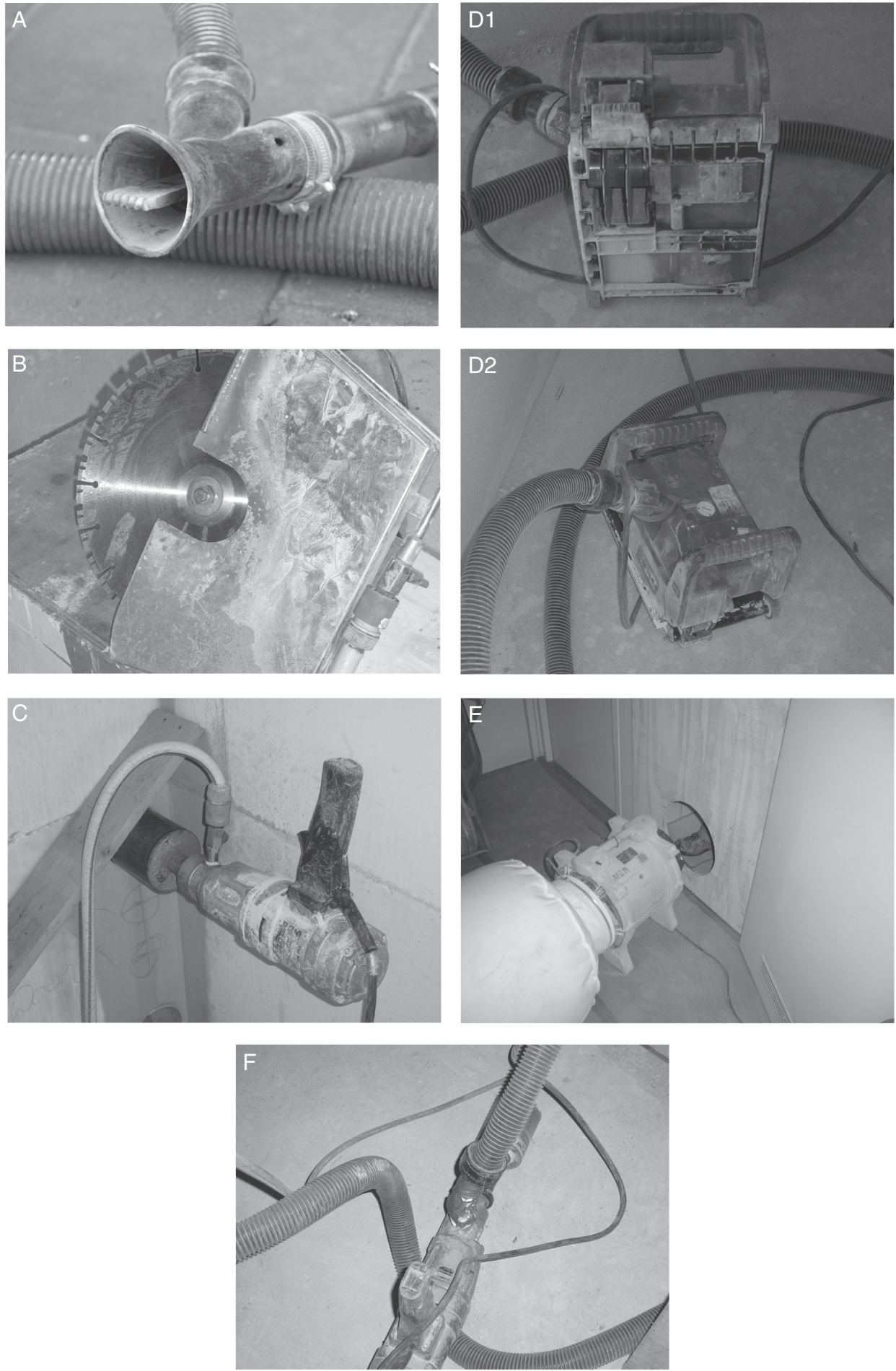

1 Illustrations of identified control measures during the baseline exposure assessment. (A) Tool-integrated local exhaust ventilation (LEV) applied to a pneumatic chipping hammer; (B) Tool-integrated water suppression applied to a circular hand saw; (C) Tool-integrated water suppression applied to a hand drill; (D) Tool-integrated LEV applied to an electric milling machine (D1: bottom view; D2: top view); (E) Stationary extraction unit; and (F) Tool-integrated LEV applied to a hand drill. 
intervention strategy that will be evaluated in a postintervention measurement study. This will eventually provide some first insight in the actual effectiveness of several of the identified control measures as well as the importance of several of the factors identified. It is foreseen that future studies can use this information and will also provide new information strengthening the knowledge on the role of different factors (technical, organisational, and psychosocial) and their interaction with respect to effective interventions.

Exposure concentrations for concrete drillers and demolishers were lower than those found in other studies in the Netherlands (Lumens and Spee, 2001; Tjoe Nij et al., 2004), and exposure levels for tuck pointers were lower than the levels reported in US construction studies (Flanagan et al., 2003; Yasui et al., 2003). These differences may be due to differences in sampling strategies (i.e. task-based versus full-shift sampling) or different exposure circumstances. This and the previous studies demonstrate that exposure levels as observed for concrete drillers, demolishers, and tuck pointers can be, to a large extent, explained by the activities performed and the control measures used. The results of this study indicate that psychosocial factors (e.g. knowledge and social influence, described in Table 2) as well as the presence or absence of constraints when using control measures are associated with the use of control measures. The proactive engagement of the employer in controlling dust exposure could not clearly and consistently be associated with exposure to respirable dust and quartz.

Exposure models generated in this study explained a considerable part of the within- and between-worker variability. The explained day-to-day variability is substantially lower for quartz compared with respirable dust although respirable dust and quartz exposure levels are strongly correlated. The difference in within-worker variability for respirable dust and quartz was also shown by a previous study (Tjoe Nij et al., 2004) and might be explained by the fact that quartz exposure is mostly related to the type of material worked on and the task performed (Tjoe Nij et al., 2004; Flanagan et al., 2006).

Several determinants (e.g. sanding, working indoors, and using tool-integrated LEV) were associated with respirable dust and quartz exposure in our final multivariate models. Among others, demolishing, milling, and worker-source orientation and workersource distance were associated with higher respirable dust levels only, whereas drilling and using tool-integrated water suppression were associated with higher quartz exposure levels. Correlation between the different determinants likely explains why some determinants are absent in our final exposure models, while an association was found in univariate models.

For instance, this study confirmed that performing abrasive tasks (e.g. drilling, sawing, jackhammering, and/or tuck pointing) increases exposure levels for respirable dust and quartz. These tasks were also identified as high exposed activities in previous studies (Akbar-Khanzadeh et al., 2002; Echt et al., 2003; Flanagan et al., 2003; Yasui et al., 2003; Croteau et al., 2004; Yassin et al., 2005). However, tasks are strongly job related, and in the final model some tasks did explain additional variability. Intercorrelations likely also explain why several determinants expected to predict respirable dust and quartz exposure, based on literature and earlier study findings, did not show any association with exposure in the multivariate model. Frequency and time spend on activities, likely sources of day-to-day variability in previous studies (Burstyn et al., 1999), were not associated with exposure to respirable dust or quartz. Equipment used appeared not to be associated with exposure although literature shows that hand-operated equipment results in higher exposure levels compared with heavy equipment (Linch, 2002; Rappaport et al., 2003). Materials with a high percentage of quartz, i.e. concrete and limesandstone, increased quartz exposure in a univariate model. However, because these materials were strongly correlated with job category, these determinants were absent in the multivariate model.

The effects of control measures were studied per job category. Limited numbers of observations per job category hampered these analyses for some jobs. However, most controls identified in this study appeared effective at reducing exposure. As can be expected, engineering control measures are less strongly associated with a significant reduction in the average exposure level over a full working day compared with task-based (peak) exposures (Rappaport et al., 2003; Tjoe Nij et al., 2003; Fransman et al., 2008). Increased respirable dust levels for demolishers, using a stationary extraction unit as control measure, are remarkable, and this relationship might be confounded by their work area. As observed in 
the walk-through survey, demolishers only used this control measure when jackhammering in a small enclosed and separated area where high dust loads could be expected (Flanagan et al., 2006). Exposure levels in the same situation without this control measure could not be estimated due to the cross-sectional nature of this study. One can assume that the use of control measures is, at least to some extent, dependent on expected exposure levels. For RPE, this may also be the case. Interestingly, concrete drillers who were not using control measures wore RPE less frequently. On the other hand, tuck pointers more frequently wore RPE when not using control measures. These findings will be taken into account to optimize and evaluate the intervention and when the exposure data are being used to estimate exposure for an individual in a job title, performing a task under certain circumstances.

Besides indications arising from the questionnaire, observations resulted in some anecdotal reports that the presence of constraints can hinder workers who are motivated to use control measures. For example, a demolisher intended to use integrated water suppression as control measure. However, the worksite had no water supply available. Another concrete driller intended to use tool-integrated LEV when working on the 18 th floor. However, the contractor gave no permission to use the elevator for this purpose. Thus, contextual factors determine the use of control measures as well.

Several studies have stressed the importance of psychosocial factors. Analyses of large databases have shown that worker behaviour is likely to explain between-worker variability and potentially also part of the within-worker variability (Kromhout and Vermeulen, 2001). Furthermore, personal factors and working techniques (i.e. work practices) might play an important role in worker's exposure, and these factors will also be important in exposure control, possibly even more than engineering controls (Rappaport et al., 1999; Burdorf, 2005). To our knowledge, this is the first study exploring the effect of psychosocial factors in relation to occupational exposure to airborne substances. The questionnaire focused on psychosocial factors was based on existing questionnaires but was not validated. As a result, misclassifications could partly explain the relatively weak association. Nevertheless, some interesting indications were observed but need confirmation in a larger study. With regard to the psychosocial factors, only knowledge showed a relation with exposure overall, with more knowledge resulting in lower exposure (univariate analysis). This might be due to training resulting in better use of control measures, but may also be due to confounding by other factors. For example, carpenters have the highest knowledge level, but they also naturally perform the lowest exposed activities. Larger social influence from co-workers and supervisors was expected to have a positive effect on exposure. This association was only observed among concrete drillers.

The use of control measures was associated with an individual's beliefs, risk perception, and/or motivation regarding the effectiveness and use of exposure controls and dust-reducing work practices. In general, interesting and somewhat unexpected associations (e.g. workers with higher knowledge levels less often used control measures, even within job categories) were found between some psychosocial factors and the use of control measures. Because these associations may be confounded by other factors, detailed contextual information is needed to interpret some of these associations. Many of these findings seem to be plausible, but more research is needed in a larger population to establish the causal role of the psychosocial factors taking into account potential confounding factors.

\section{CONCLUSION}

In conclusion, we identified determinants of respirable dust and quartz exposure in the construction industry that are relevant for designing an intervention strategy. Although a larger study population is required to determine relations between organizational and psychosocial factors univocally, and between psychosocial aspects and the use of control measures, this study did give indications that psychosocial factors, i.e. knowledge and social influence, may play a role in quartz exposure levels in the construction industry. In the intervention phase of this study, the focus will be directed towards the interplay between technical, organizational, and psychosocial factors. In general, the influence of constraints impeding and factors that facilitate the use of control measures, whether on an individual, work environment, or organizational level, will be optimized. 


\section{SUPPLEMENTARY DATA}

Supplementary data can be found at http://annhyg. oxfordjournals.org/.

\section{FUNDING}

ZonMw (20802002).

\section{ACKNOWLEDGEMENTS}

The authors first of all thank all the companies and workers who participated in the study. Furthermore, the authors thank the students who visited the many worksites. We also acknowledge Jody Schinkel for his advice with regard to the data collection and database building, and we wish to thank Laurens Clignett for his valuable input regarding worker behaviour and psychosocial determinants.

\section{REFERENCES}

Ajzen I. (1991) The theory of planned behaviour. Organ Behav Hum Decis Process; 50: 179-211.

Akbar-Khanzadeh F, Brillhart RL. (2002) Respirable crystalline silica dust exposure during concrete finishing (grinding) using hand-held grinders in the construction industry. Ann Occup Hyg; 46: 341-6.

Anonymous. (2007) OHSAS 18001 Occupational health and safety management-requirements. Delft: Nederlands Normalisatie-instituut (NEN). pp. 1-32.

Brown T. (2009) Silica exposure, smoking, silicosis and lung cancer-complex interactions. Occup Med (Lond); 59: $89-95$.

Brun E, Op dB, van Herpe S et al. (2009) Expert forecast on emerging chemical risks related to occupational safety and health. Luxembourg: European Agency for Safety and Health at Work. ISBN 978-92-9191-171-4, 1-198.

Burdorf A. (2005) Identification of determinants of exposure: consequences for measurement and control strategies. Occup Environ Med; 62: 344-50.

Burstyn I, Heederik D, Bartlett K et al. (1999) Wheat antigen content of inhalable dust in bakeries: modeling and an inter-study comparison. Appl Occup Environ Hyg; 14: 791-8.

Croteau GA, Flanagan ME, Camp JE et al. (2004) The efficacy of local exhaust ventilation for controlling dust exposures during concrete surface grinding. Ann Occup Hyg; 48: 509-18.

Echt A, Sieber K, Jones E et al. (2003) Control of respirable dust and crystalline silica from breaking concrete with a jackhammer. Appl Occup Environ Hyg; 18: 491-5.

Ehrlich RI, Myers JE, te Water Naude JM et al. (2011) Lung function loss in relation to silica dust exposure in south african gold miners. Occup Environ Med; 68: 96-101.
Fedotov IA, Eijkermans GJM. (2007) Elimination of silicosis. Issue No. 12. Available at http://www.who.int/occupational_health/publications/newsletter/gohnetarchives/ en/. Accessed 27 December 2012.

Flanagan ME, Seixas N, Becker P et al. (2006) Silica exposure on construction sites: results of an exposure monitoring data compilation project. J Occup Environ Hyg; 3: 144-52.

Flanagan ME, Seixas N, Majar M et al. (2003) Silica dust exposures during selected construction activities. AIHA J (Fairfax, Va); 64: 319-28.

Fransman W, Schinkel J, Meijster T et al. (2008) Development and evaluation of an exposure control efficacy library (ECEL). Ann Occup Hyg; 52: 567-75.

Geer LA, Anna D, Curbow B et al. (2007) Survey assessment of worker dermal exposure and underlying behavioral determinants. J Occup Environ Hyg; 4: 809-20.

George D, Mallery P. (2010) SPSS for windows step by step: a simple guide and reference, 18.0 update. Boston, MA: Allyn \& Bacon.

Gliem JA, Gliem RR. (2003) Calculating, interpreting, and reporting cronbach's alpha reliability coefficient for likerttype scales. Presented at the Midwest Research-to-Practice Conference in Adult, Continuing, and Community Education, October 8-10. Columbus, OH: The Ohio State University.

Goldenhar LM, LaMontagne AD, Katz T et al. (2001) The intervention research process in occupational safety and health: an overview from the national occupational research agenda intervention effectiveness research team. J Occup Environ Med; 43: 616-22.

Health and Safety Executive (HSE). (2000) Methods for the determination of hazardous substances (MDHS) 14/3general methods for sampling and gravimetric analysis of respirable and inhalable dust. ISBN 0-7176-1749-1. pp. 1-12. Available at http://www.hse.gov.uk/pubns/mdhs/pdfs/ mdhs14-3.pdf. Accessed 27 December 2010.

Health and Safety Executive (HSE). (2005) Methods for the determination of hazardous substances (MDHS) 101-crystalline silica in respirable airborne dusts. ISBN 0-7176-28973. pp. 1-16. Available at http://www.hse.gov.uk/pubns/ mdhs/pdfs/mdhs101.pdf. Accessed 27 December 2010.

Heederik D, van Rooy F. (2008) Exposure assessment should be integrated in studies on the prevention and management of occupational asthma. Occup Environ Med; 65: 149-50.

Heederik D, Henneberger PK, Redlich CA; ERS Task Force on the Management of Work-related Asthma. (2012) Primary prevention: exposure reduction, skin exposure and respiratory protection. Eur Respir Rev; 21: 112-24.

Kristensen TS. (2005) Intervention studies in occupational epidemiology. Occup Environ Med; 62: 205-10.

Kromhout H, Vermeulen R. (2001) Temporal, personal and spatial variability in dermal exposure. Ann Occup Hyg; 45: 257-73.

LaMontagne AD, Stoddard AM, Youngstrom RA et al. (2005) Improving the prevention and control of hazardous 
substance exposures: a randomized controlled trial in manufacturing worksites. Am J Ind Med; 48: 282-92.

Lazovich D, Parker DL, Brosseau LM et al. (2002) Effectiveness of a worksite intervention to reduce an occupational exposure: the minnesota wood dust study. Am J Public Health; 92: 1498-505.

Linch KD. (2002) Respirable concrete dust-silicosis hazard in the construction industry. Appl Occup Environ Hyg; 17: 209-21.

Lumens M, Maas J, Siegert H et al. (2009) Dossier kwarts. Available at http://www.arbokennisnet.nl/kennisdossier gevaarlijke_stoffen.html. Accessed 19 November 2010.

Lumens ME, Spee T. (2001) Determinants of exposure to respirable quartz dust in the construction industry. Ann Occup Hyg; 45: 585-95.

Maciejewska A. (2008) Occupational exposure assessment for crystalline silica dust: approach in Poland and worldwide. Int J Occup Med Environ Health; 21: 1-23.

Meertens RM, Lion R. (2008) Measuring an individual's tendency to take risks: the risk propensity scale. J Appl Soc Psychol; 38: 1506-20.

Rappaport SM, Goldberg M, Susi P et al. (2003) Excessive exposure to silica in the US construction industry. Ann Occup Hyg; 47: 111-22.

Rappaport SM, Weaver M, Taylor D et al. (1999) Application of mixed models to assess exposures monitored by construction workers during hot processes. Ann Occup Hyg; 43: 457-69.
Rushton L. (2007) Chronic obstructive pulmonary disease and occupational exposure to silica. Rev Environ Health; 22: 255-72.

Seixas NS, Neitzel R, Stover B et al. (2011) A multi-component intervention to promote hearing protector use among construction workers. Int J Audiol; 50 (Suppl. 1): S46-56.

Tjoe Nij E, Hohr D, Borm P et al. (2004) Variability in quartz exposure in the construction industry: implications for assessing exposure-response relations. J Occup Environ Hyg; 1: 191-8.

Tjoe Nij E, de Meer G, Smit J et al. (2003) Lung function decrease in relation to pneumoconiosis and exposure to quartz-containing dust in construction workers. Am J Ind Med; 43: 574-83.

Tjoe Nij E, Hilhorst S, Spee T et al. (2003) Dust control measures in the construction industry. Ann Occup Hyg; 47: 211-8.

Vida S, Pintos J, Parent ME et al. (2010) Occupational exposure to silica and lung cancer: pooled analysis of two case-control studies in montreal, canada. Cancer Epidemiol Biomarkers Prev; 19: 1602-11.

Yassin A, Yebesi F, Tingle R. (2005) Occupational exposure to crystalline silica dust in the United States, 1988-2003. Environ Health Perspect; 113: 255-60.

Yasui S, Susi P, McClean M et al. (2003) Assessment of silica exposure and engineering controls during tuckpointing. Appl Occup Environ Hyg; 18: 977-84. 